\title{
A relação entre o Estado e as organizações sociais de saúde na Amazônia
}

Recebido: 28 jan 2019 Aceito: 10 fev 2019

Autor de

correspondência:

andreaferreira72@yahoo.com.br

Conflito de interesses: Os autores declaram não haver nenhum interesse profissional ou pessoal que possa gerar conflito de interesses em relação a este manuscrito.
${ }^{(1)}$ Programa de Pós-graduação em Serviço Social - PPGSS, Universidade Federal do Pará - UFPA, Belém, PA, Brasil.

\section{Resumo}

A forma que o Estado assume na contemporaneidade e, por conseguinte seu novo padrão de política social é forjada pelas mudanças no padrão da produção. O artigo em tela busca analisar o Estado sob ângulo do vivido hoje, se apropria de análises teóricas críticas do Estado enquanto categoria abstrata, mas enfatiza no estudo das determinações que configuram o Estado tal como se apresenta na era da financeirização e sua relação com a sociedade civil, em particular, através das Organizações Sociais (OS) e sua atuação nas políticas públicas de saúde a partir do processo de publicização iniciado na década de 1990 sob o projeto de reforma gerencial do Estado brasileiro. Objetivo: realizar o estudo sobre as Organizações Sociais de Saúde (OSS) no Brasil e na Amazônia, com destaque para o estado do Pará e tem como objetivo caracterizar suas formas de ser na relação com o Estado. Método: com objetivo de se aproximar da realidade das OSS na chamada Amazônia Legal (Amazonas, Amapá, Mato Grosso, Pará, Rondônia, Roraima, Tocantins e Maranhão) realizou breve pesquisa exploratória através da análise de dados secundários disponibilizados pelas i) secretarias estaduais de saúde, em seus canais oficiais de comunicação; ii) das informações contidas nas legislações específicas de cada estado; iii) das informações dos órgãos de controle externo e iv) de dados oficiais do Cadastro Nacional de Estabelecimentos de Saúde - CNES/DATASUS, do Ministério da Saúde. A partir do levantamento no banco de teses e dissertações da Coordenação de Aperfeiçoamento de Pessoal de Nível Superior - CAPES de trabalhos que estudaram as OSS, de 2012 a 2018, se realizou breve estado da arte da produção científica no Brasil, analisando os resultados das pesquisas das 10 teses encontradas. Resultados: as informações iniciais apontam que esta região, assim como a região sudeste possui histórico de realização de contratos de gestão com as OSS, predominantemente, nos serviços de atenção à saúde de média e alta complexidade. O estado do Pará foi pioneiro em instituir no seu ordamento jurídico estadual as Organizações Sociais, a Lei Complementar $n^{\circ} 5.580$ de 19/07/96 autorizou a qualificação como OS de pessoas jurídicas de direito privado sem fins lucrativos, cujas atividades sejam dirigidas a prestação de serviços gerais. Atualmente, o governo estadual mantém 16 contratos de gestão e dezenas de aditivos distribuídos entre duas OS, sendo uma responsável por oito contratos e outra por sete e uma terceira possui apenas um contrato de 
gestão. Neste estado, $96 \%$ da força de trabalho dos hospitais regionais é contratada pelas OSS. Além dos contratos por prazo determinado com os profissionais que realizam a assistência em saúde e apoio administrativo, as OSS quarterizam outros serviços como lavanderia, segurança, transporte etc. A base de dados do CNES também informa que alguns hospitais possuem profissionais de saúde contratados via cooperativas. A forma de ser das Organizações Sociais de Saúde na relação com o Estado, analisadas por este estudo sob a perspectiva da história, leva a compreensão de que entidades não correspondem a forma de "pessoas jurídicas de direito privado, sem fins lucrativos" como menciona a lei, mas atuam como organizações competitivas, com modelos gerenciais de empresas privadas, com parâmetros de mercado para remuneração da força de trabalho e com a permissão do Estado para investir no mercado financeiro. A relação do Estado com o terceiro setor, representadas no presente estudo pelas Organizações Sociais de Saúde, expressa nos estudos acadêmicos sobre as OSS no Brasil e no panorama da atuação destas entidades na Amazônia, em especial, no estado do Pará, mostra apenas sumariamente a face aparente do fenômeno chamado "contrarreforma do Estado" cuja principal chave heurística está na relação mutuamente determinante entre a estrutura econômica e a superestrutura jurídico-política e ideológica da sociedade. Considerações Finais: os serviços de saúde executados pelas Organizações Sociais, nas esferas estaduais e municipais, em diferentes níveis de atenção à saúde, representam, ou pelo menos ainda representam, a materialização de um direito social conquistado nos tempos em que a dinâmica da luta de classes no Brasil tinha outros nuances, onde os tons da resistência dos trabalhadores eram mais intensos devido a condições concretas mais adversas. Entretanto, a saúde pública brasileira sofreu alguns golpes após a consagração na Constituição Federal de 1988, para além da chamada publicização pela via das OSS analisadas aqui, há o ataque ao financiamento da seguridade social pelo mecanismo da Desvinculação de Receitas da União - DRU desde a década de 1990, pela permissão da participação direta ou indireta, inclusive controle, de empresas ou de capital estrangeiro na assistência à saúde a partir de 2015 e pela promulgação mais recente da Emenda Constitucional $n^{\circ} 95$, chamada de teto dos gastos públicos. Os acontecimentos do tempo presente no Brasil, requisitam dos partidos políticos, movimentos sociais, sindicatos, pesquisadores e demais atores sociais do campo progressista retornarem à análise das lutas de classe e de suas expressões contraditórias, sobretudo, do Estado como condensação desta relação.

Descritores: Política de Saúde; Administração em Saúde; Administração de serviços de saúde. 